\title{
The way of old bread recycling in the bread making
}

\author{
Olesia Savkina*, Lina Kuznetsova, Marina Lokachuk, Olga Parakhina, Elena Pavlovskaya, and Natalia Lavrenteva
}

St. Petersburg branch State Research Institute of Baking Industry, Podbelskogo highway 7, 196608, St.Petersburg, Pushkin, Russian Federation

\begin{abstract}
The recycling of non-standard bread (with cracked crust, unsatisfactory mass or non-standard shape) saves natural food resources and provides economic benefits for bakers. The objective of this study was to investigate the impact of recycled old bread on the quality of sourdough and bread. An increase in the bread dosage in the rye dense sourdough more than $25 \%$ instead of flour negatively affected sourdough quality. The deterioration of the sourdough quality was not associated with a nutrient deficiency. When $25 \%$ of recycling old bread was in the sourdough, the quality of the bread was comparable to the control, but the crumbliness was 1.5 times less compared to the control, which indicates a slowing down of the staling process in bread made with recycled bread in sourdough. Bread fermentation in sourdough allowed getting bread with a good smell and taste. Old recycled bread did not significantly affect the microbial contamination of new bread, especially in terms of moulds and yeasts.
\end{abstract}

\section{Introduction}

In the baking industry, substandard bread (production defects), bread returned from the distribution network and returnable production waste can be used for processing. Substandard bread, waste and bread from the distribution network may be processed into bread crumbs, crumbs and special semi-finished product (soaked bread) [1-3].

In the Russian Federation, in accordance with the "Rules for the Organization and Conducting the Technological Process at the Bakery Enterprises", insufficient quality bread is recycled in the next way: soaked bread mix, crackers and bread crumbs are prepared and used when dough mixed [1]. Bread crumbs are used to sprinkle conveyor belts, to produce bread kvass (beverages). Bread crumbs also sold at the market for home cooking $[1,2,4]$. Bread is used for the production of hydrolysates, which are used for sourdough. They are also saccharified by enzymes and used in the dough preparation. This allows intensifying the process of bread making [4-6].

Only fresh bread within the shelves life date is allowed to recycling in Russia. While in Europe, there are no strict requirements for the bread recycling in the bread making enterprises: it is allowed to process even stale bread. For example, methods have been developed for the sourdough preparation using stale bread $[2,8,9]$.

The German company IsernHäger developed liquid rye sourdough IBF based on bread fermentation. Old bread is used in an amount of $15-50 \%$ of the total amount of sourdough. Ferment has a self-preserving ability and retains its properties within 144 hours. The use of old bread allows saving raw materials, to improve the bread flavor and to increase the bread freshness during storage [8, 9].

Recycled bread in bakery is undoubtedly economically beneficial for the manufacturer. However, the following difficulties are possible when recycles bread. The quality of recycled bread is inferior to the quality of ingredients, and this directly affects the quality of bread. If the bread stays on the trading shelves too long, its quality decreases. The bread becomes hard, crumbling, the crust loses its luster and brittleness, becomes soft, wrinkled, and its taste and smell worsen. The specific aroma and taste of stale bread appear due to the loss and destruction of part of aromatic substances. The use of stale bread can adversely affect the smell and taste of a freshly baked bread made using it [1-3].

The second aspect is various bread diseases during storage. Bread is affected by molds and becomes unsuitable for eating. Most often, mold must be caused by fungi of the genera Aspergillus, Penicillium, Mucor, Rhizopus [9-11]. It is observed when storing bread in damp, poorly ventilated areas. The fungal mycelium spreads over the surface of the bread, forming fluffy or velvety deposits of different colors. Fungi enzymes break down proteins, fats and carbohydrates, which leads to a deterioration in the bread consumer properties and to the appearance of an unpleasant musty smell and taste $[9,10]$. In addition, some types of molds produce toxic substances - mycotoxins, which resist to heating, and therefore can remain in the bread even after baking. Therefore, the recycling of mold-affected bread is unacceptable [9-11].

Another serious disease affecting bakery products, mainly from wheat flour, is ropy-bread disease. The causative agents of the disease are spore-forming bacteria Bacillus subtilis. Bread affected by this disease

\footnotetext{
*Corresponding author: 1103savkina@mail.ru
} 
acquires an unpleasant taste and smell, the crumb becomes viscous, sticky. In addition, the causative agents of potato bread disease form substances that cause digestive upset. Bread infected with ropy disease is not suitable for food and processing.

The third type of microbial spoilage is the lime disease. It appears on the surface of the crust or crumb of bread in the form of a white, dry, powdery coating, similar to crushed chalk or lime. The causative agents of the disease are some ascomycetes or imperfect yeasts. Yeast species Endomyces chodacii, Endomycopsis fibuliger, Hyphopichia burtonii, Debaryomyces occidentalis, Saccharomyces fibuligera are named as causative agents of lime disease [9, 10].

The disadvantages of using soaked bread, bread crush and bread crumbs is that the bread dosage does not exceed 10\%. When using soaked bread (a special semifinished product in Russia), spore-forming bacteria, yeast and molds can develop in it, which can causing bread microbial spoilage and moldy taste and smell in the bread [9].

When applying bread crumbs and bread crush, it is possible to increase crumbliness, vulnerability to mold during storage, speed up the staling process, and cause bad taste and smell of stale bread.

The probability of occurrence of these drawbacks depends on many factors - the ratio of different types of products in the recycling batch, their recipes, bread quality, freshness and microbiological contamination of bread. Thus, all this somewhat limits the possibilities of bread recycling at enterprises by existing methods [1].

Therefore, the development of resource-saving technologies to increase the number of recyclable bread in the dough, to improve the quality of bread and improve microbiological safety, is very relevant.

The aim of this research was to study the impact of recycled old bread on the quality of sourdough and bread.

\section{Materials and methods}

\subsection{Bread making procedure}

The influence of recycled bread on the bread quality and its microbiological safety was investigated. The control was bread made using traditional rye dense sourdough. Sourdoughs were prepared using pure cultures of lactic acid bacteria and yeast from the collection of the St. Petersburg branch State Research Institute of Baking Industry (Russia). Experimental sourdough was prepared using processed bread in an amount of $3.6-10 \mathrm{~kg}$.

\subsubsection{Starter cultures and sourdough}

Controls were rye dense sourdough with humidity levels of $50 \%$., Sourdough with recycled old bread crumbs were used as experimental samples. The control sourdough was prepared in accordance with the official instructions for Russian baking companies with the use of micro-organism starter cultures from the collection of the St Petersburg branch of the State Research Institute of the Baking Industry [13]. Lactic acid and yeast bacteria starter cultures have been widely used for many years as symbiotic compositions in bakery companies in Russia [9, 13].

Three strains of lactic acid bacteria - L brevis $5, L$ brevis 78 , and $L$ plantarum 63 - and one strain of yeast $C$ milleri - were used for the dense rye sourdough with a humidity level of 50\% (Kosovan, 2008).

In experimental sourdough samples 15, 20, 25, 35, 50 and $100 \%$ flour were replaced by old recycling bread crumbs.

\subsubsection{Dough preparing}

The formulations for the rye-wheat bread are presented in Table 1.

Table 1. The formulations of rye-wheat bread.

\begin{tabular}{|c|c|c|c|}
\hline $\begin{array}{c}\text { Raw materials, } \\
\%\end{array}$ & $\begin{array}{c}\text { Control } \\
\text { bread }\end{array}$ & $\begin{array}{l}\text { Bread with } \\
25 \% \text { of } \\
\text { recycling } \\
\text { old bread } \\
\text { in dough }\end{array}$ & $\begin{array}{l}\text { Bread with } \\
25 \% \text { of } \\
\text { recycling old } \\
\text { bread in } \\
\text { sourdough }\end{array}$ \\
\hline Rye flour & 35 & 35 & 35 \\
\hline Wheat flour & 40 & 40 & 40 \\
\hline Sourdough & 40 & 40 & - \\
\hline $\begin{array}{l}\text { Sourdough with } \\
25 \% \text { of old bread }\end{array}$ & - & - & 40 \\
\hline Old bread crunbs & - & 50 & 25 \\
\hline Yeast & 0.5 & 0.5 & 0.5 \\
\hline Salt & 1.4 & 1.4 & 1.4 \\
\hline Water & \multicolumn{3}{|c|}{ until dough humidity of $43 \%$} \\
\hline
\end{tabular}

The required quantity of sourdough was mixed with flour, yeast, salt, and water, until the dough achieved a humidity level of $43 \%$. After mixing, the dough samples were shaped into $400 \mathrm{~g}$ loaves, placed in aluminum pans and leavened at $30^{\circ} \mathrm{C}$ until the volume was twice that of the initial volume. The leavened dough samples were cooked in an oven at $210^{\circ} \mathrm{C}$ for eighteen minutes.

\subsection{Sourdough and dough assessments}

An assessment was carried out on the quality of the sourdough and dough by making use of the following properties: acidity was determined by titration, using a $0.1 \mathrm{n}$. solution of $\mathrm{NaOH}[14]$. The lifting capacity was determined by the rate at which it rose in a glass of water at a temperature of $32^{\circ} \mathrm{C}$ for a $10 \mathrm{~g}$ mass of dough shaped into a ball and with a humidity level of $45 \%$ [14]. The increase in volume was calculated by the ratio between the final volume and the initial volume multiplied by $100 \%$.

To determine the lactobacilli and yeast proportion in asourdough, the method of microscopy and counting in a fixed colored preparation in 50 fields of view was used [10]. 


\subsection{Assessment of baked bread}

\subsubsection{Assessment of quality}

The assessment of bread quality was carried out in relation to the following properties: organoleptic appearance (shape, surface, crumb color), condition of crumb (porosity and texture), taste and smell; physicchemical and physical. Acidity was determined by titration, using a $0.1 \mathrm{~N}$ solution of $\mathrm{NaOH}$ [14], porosity was determined as the ratio of pore volume to the total volume of products, pore volume - as the difference between the volume of product and the volume of nonporous mass, specific volume - as the ratio of product volume to $100 \mathrm{~g}$ of bread, compressibility was determined on the automatic penetrometer Labor (Hungary). The crumbliness of the crumb was investigated in a $72 \mathrm{~h}$ of storage. It was determined by the ratio of the crumbs mass to the mass of the sample when slicing bread [14].

The content of volatile acids was determined by neutralizing the evaporated volatile acid using a $0.1 \mathrm{n}$. solution of $\mathrm{NaOH}$. The alcohol content was determined by using the iodometric method which is based on the quantity of sodium thiosulfate spent in titration.

\subsubsection{Sensory evaluation}

The panel of 10 non-specialists was used to evaluate the sensory characteristics of the bread. Then, they were asked to evaluate separately appearance (shape, surface, crumb color) and the crumb (color, smell, taste, chewiness and porosity). The ranking scale ranged from 1 to 5 (5-like extremely, 4.5-like very much, 4-like moderately, 3.5-like slightly, 3-neither like not dislike, 2.5-dislike slightly, 2-dislike moderately, 1.5-dislike very much, 1-dislike extremely).

\subsubsection{Mould spoilage assessment}

\subsubsection{Determining the microbial contamination of baked bread}

Microbial contamination of wheat and rye bread were studied. The bread was prepared for microbiological analysis in the following way: immediately after baking in the opening of the oven, the loaves were packed into sterile paper, placed in a sterile room, and cooled to a temperature of between $25-28^{\circ} \mathrm{C}$. After cooling, the bread was cut in sterile conditions. A total of $10 \mathrm{~g}$ of bread was added to $100 \mathrm{ml}$ of sterile water and diluted to between $10^{1}-10^{6}$ degrees. From each dilution a $0.1 \mathrm{ml}$ suspension was added to the surface of the meat-peptone agar in a Petri dish (for spore-forming bacteria assessment), and $1 \mathrm{ml}$ of the suspension was introduced into a Petri dish and poured on top of malt agar which contained a total of $8 \%$ of dry solids (for yeast and mould assessment).

\subsubsection{Determining of rate of appearance of mould spoilage}

The impact of the old bread on mould disease of new bread was investigated. Sterile bread slices were contaminated by a pure culture of the mould Penicillium chrysogenum. Immediately after baking in the oven opening, the loaves were packed into sterile paper, placed in a sterile room, and cooled to a temperature of between $25-28{ }^{\circ} \mathrm{C}$. After cooling the bread was cut in a sterile environment, with slices being taken at a size of $3.5 \times 6.5 \mathrm{~cm}$ and at a thickness of $0.3-0.4 \mathrm{~cm}$. The slices were placed in sterile Petri dishes. An aqueous suspension of a pure culture of the mould, Penicillium chrysogenum, was prepared for the infection of slices of bread. The biomaterial of Penicillium chrysogenum was transferred from a tube containing a pure culture of mould grown on malt agar to $1 \mathrm{ml}$ of sterile water using 'Tween-80' and was thoroughly suspended. The suspension was inoculated into each slice of bread in three shots using a microbiological needle. Petri dishes with infected slices were incubated at a temperature of $25 \pm 1{ }^{\circ} \mathrm{C}$ until the first signs appeared of a growth of mould colonies [15].

\subsection{Statistical analysis of the data}

All of the experiments were carried out a total of five times. Statistical analysis was performed using Excel software. Comparison of the influence of factors was carried out by the method with significance tested at the 95\% confidence level and differences among means were determined using the least significant difference and Duncan's test of two-factor analysis of variance with one repetition (ANOVA). The confidence intervals shown in the histograms and in the table reflect the accuracy of the used methods.

The accuracy of the experimental data was evaluated by using mathematical statistical methods in Microsoft Excel (2010 version) at a theoretical frequency of 0.95. Results were given as mean \pm standard deviation.

\section{Results}

Yeast and non-spore-forming bacteria were found in old bread used for recycling. To determine the effect of the recycling bread on the microbial contamination of the new bread made with it, the crumb of bread was tested immediately after baking the samples. Spore-forming bacteria, yeasts and molds were not detected. The data obtained indicates the inhibition of these microorganisms in the baking process. Thus, the introduction of old bread in a sourdough didn't increase the risk of microbial bread contamination.

The impact of the old bread quantity in dense rye sourdough on sourdough biotechnological indicators was investigated.

It was found that when the old bread in the sourdough was more than $25 \%$, acid accumulation slowed down (Fig. 1), the lifting force worsened (Fig. 2), and increased sourdough less in volume (Fig. 3). 
The data showed that the use of $25 \%$ of old bread is optimal. The content of lactic acid bacteria and yeast was comparable in the control and experimental sourdoughs with $25 \%$ of old bread and amounted $(3.5 \pm 0.5) \cdot 10^{9} \mathrm{CFU} \cdot \mathrm{g}-1$ and $(30.5 \pm 0.5) \cdot 10^{6} \mathrm{CFU} \cdot \mathrm{g}-1$, respectively.

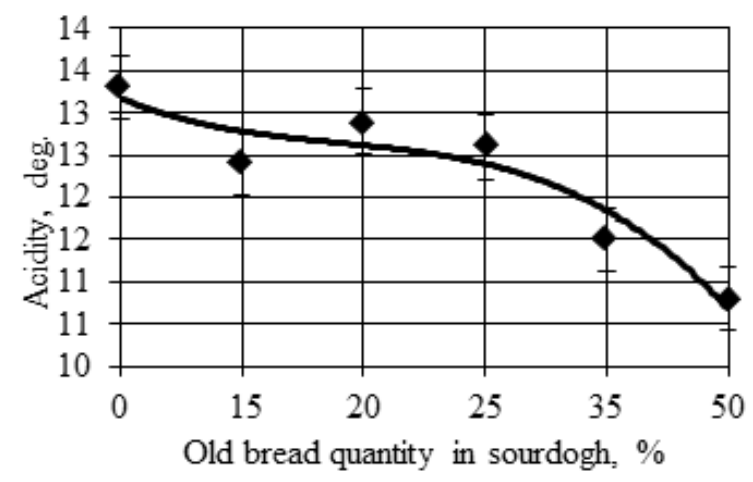

Fig. 1. The effect of the old bread quantity on the acidity of dense rye sourdough.

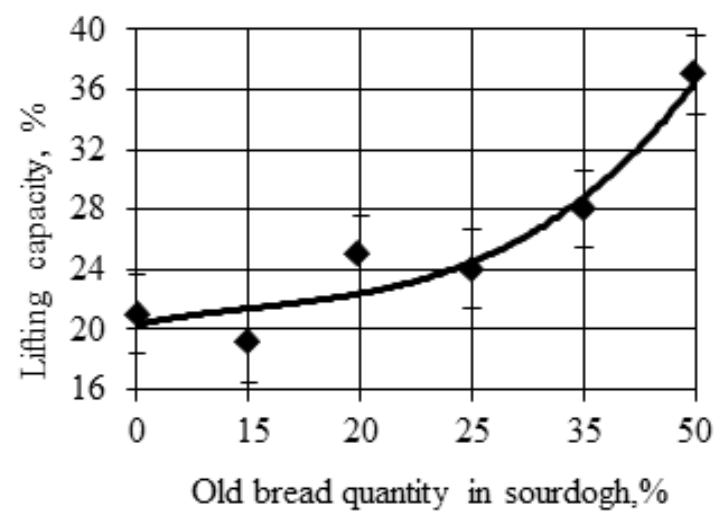

Fig. 2. The effect of the old bread quantity on the lifting capacity of dense rye sourdough.

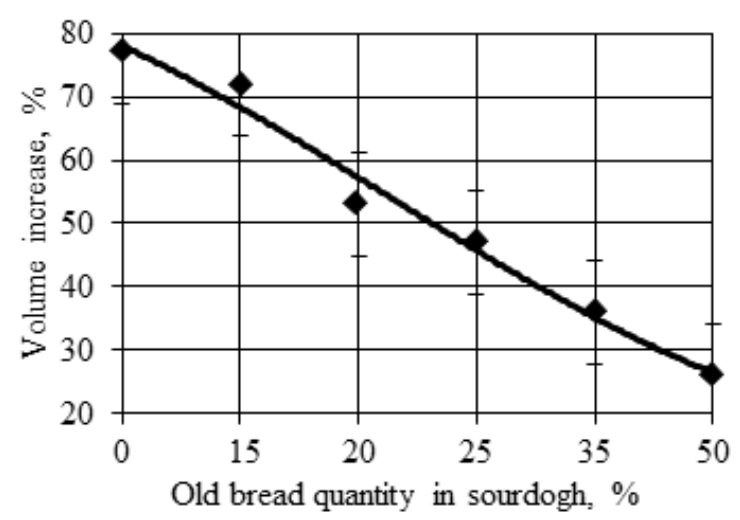

Fig. 3. The effect of the old bread quantity on the dense rye sourdough volume.

To identify the causes of deterioration in the sourdough quality, when the bread content in it was more than $25 \%$, the content of reducing sugars and amine nitrogen was studied in mixtures of flour, water and bread (which are a nutrient medium for starter microorganisms). The content of reducing sugars in the samples made with old bread in sourdough was higher than in the control sample (Fig.4). As the amount of old bread increased, the content of reducing sugars increased. When old bread was $100 \%$ instead of flour, a reduction in reducing sugars was observed. However, it was still higher than in the control without old bread.

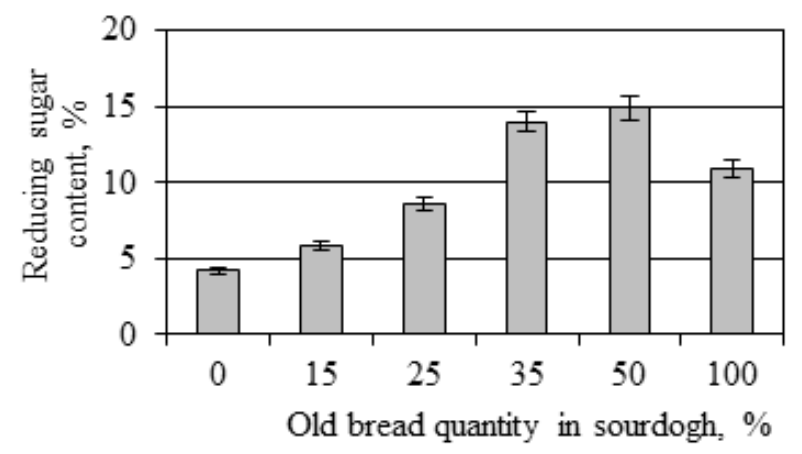

Fig. 4. The effect of the amount of old bread on the reducing sugar content in the mixture for dense rye sourdough.

Amine nitrogen content increased as old bread content increased (Fig.5). Data obtained shown that with an increase in the content of old bread in sourdough, there was no decrease in nutrients for lactic acid bacteria and yeast (reducing sugars and amine nitrogen). Therefore, the deterioration of the sourdough quality was not associated with a nutrient deficiency.

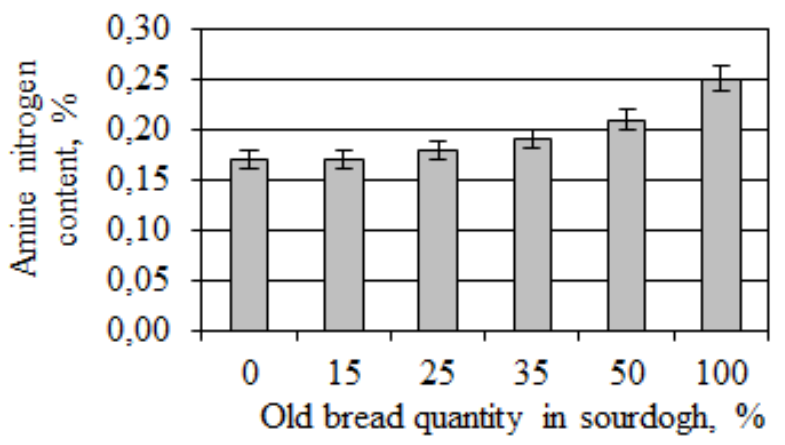

Fig. 5. The effect of the amount of old bread on the amine nitrogen content in in the mixture for dense rye sourdough.

The influence of processed old bread on the quality of dough and bread has been studied (Table 2). When old bread was added to the dough, the dough had less acidity and lower lifting capacity than control, while the dough made using sourdough with old bread had indicators comparable with control.

When the recycling old bread was in the sourdough, the acidity, porosity, specific volume and compressibility of the bread was comparable to the control, as well as content of alcohol and volatile acid. However, the crumbliness of the experimental bread samples was 1.5 times less compared to the control, which indicates a slowing down of the staling process in bread made with recycled bread.

When the old bread was added not in the sourdough, but in the dough, the quality of the bread deteriorated compared to the control.

Sensory characteristics of bread are also presented at Table 2. Control bread and bread made with old bread in 
sourdough had comparable characteristics. They had the better crust shape, surface, crust color, taste, odour, chewiness and porosity than the bread made with old bread in dough, which had unpleasant smell of staling bread.

It was found that when old bread was added to the sourdough, and not to the dough, the compressibility of the crumb during storage changed as well as in the control (Fig.6). And when bread was added to the dough, the compressibility was worse.

The effect of the old bread on the bread resistance to the moulds was established. Fermentation of old bread in sourdough allowed decrease microbial spoilage. When contaminated bread by Penicillium chrysogenum, the growth of mould colonies wasn't observed during entire storage period (until total slice staling ) in the slices of control bread and bread made with old bread in sourdough. On bread made with old bread in the dough, mould colonies were observed in a 6 days.

Table 2. Dough and bread quality indicators.

\begin{tabular}{|c|c|c|c|}
\hline Indicators & $\begin{array}{l}\text { Control } \\
\text { bread }\end{array}$ & \begin{tabular}{|} 
Bread with \\
$25 \%$ of \\
recycling old \\
bread in dough
\end{tabular} & $\begin{array}{c}\text { Bread with } 25 \% \\
\text { of recycling old } \\
\text { bread in } \\
\text { sourdough }\end{array}$ \\
\hline \multicolumn{4}{|c|}{ Dough } \\
\hline Acidity, degrees & $9.0 \pm 0.1^{\mathrm{a}}$ & $8.0 \pm 0.1^{\mathrm{b}}$ & $8.9 \pm 0.1^{\mathrm{a}}$ \\
\hline $\begin{array}{l}\text { Lifting capacity, } \\
\text { min }\end{array}$ & $14 \pm 1^{\mathrm{a}}$ & $19 \pm 1^{b}$ & $13 \pm 1^{\mathrm{a}}$ \\
\hline \multicolumn{4}{|c|}{ Bread } \\
\hline Acidity, degrees & $7.4 \pm 0.1^{\mathrm{a}}$ & $7.0 \pm 0.1^{\mathrm{b}}$ & $7.4 \pm 0.1^{\mathrm{a}}$ \\
\hline Porocity, $\%$ & $69 \pm 2^{\mathrm{a}}$ & $63 \pm 2^{\mathrm{b}}$ & $68 \pm 2^{\mathrm{a}}$ \\
\hline $\begin{array}{l}\text { Specific volume, } \\
\mathrm{cm} 3 \mathrm{~g} \mathrm{~g}^{-1}\end{array}$ & $2.0 \pm 0.2^{\mathrm{a}}$ & $1.9 \pm 0.2^{\mathrm{a}}$ & $2.0 \pm 0.2^{\mathrm{a}}$ \\
\hline \begin{tabular}{|c|} 
Quantity of \\
alcohol, \% of dried \\
weight
\end{tabular} & $0.28 \pm 0.03^{\mathrm{a}}$ & $0.20 \pm 0.01^{\mathrm{b}}$ & $0.30 \pm 0.02^{\mathrm{a}}$ \\
\hline $\begin{array}{l}\text { Volatile acids, \% } \\
\text { of the total acidity }\end{array}$ & $28.2 \pm 0.2^{\mathrm{a}}$ & $27.1 \pm 0.1^{\mathrm{b}}$ & $27.9 \pm 0.3^{\mathrm{a}}$ \\
\hline $\begin{array}{l}\text { Compressibility, } \\
\text { unite of device }\end{array}$ & $41 \pm 2^{\mathrm{a}}$ & $32 \pm 3^{b}$ & $40 \pm 3^{\mathrm{a}}$ \\
\hline Crumbliness, $\%$ & $5.3 \pm 0.2^{\mathrm{a}}$ & $5.5 \pm 0.2^{\mathrm{a}}$ & $3.1 \pm 0.2^{\mathrm{b}}$ \\
\hline \multicolumn{4}{|c|}{ Bread sensory characteristics } \\
\hline \multicolumn{4}{|c|}{ Crust } \\
\hline Shape & $\begin{array}{c}4.80 \pm 0.18 \\
\mathrm{a}\end{array}$ & $4.20 \pm 0.13^{b}$ & $4.81 \pm 0.22^{\mathrm{a}}$ \\
\hline Surface & $\begin{array}{c}4.80 \pm 0.18 \\
\mathrm{a}\end{array}$ & $4.20 \pm 0.13^{b}$ & $4.81 \pm 0.22^{\mathrm{a}}$ \\
\hline Color & \begin{tabular}{|c|}
$4.27 \pm 0.16$ \\
$\mathrm{a}$
\end{tabular} & $4.22 \pm 0.16^{\mathrm{a}}$ & $4.29 \pm 0.04^{\mathrm{a}}$ \\
\hline \multicolumn{4}{|c|}{ Crumb } \\
\hline Color & $3.5 \pm 0.10^{\mathrm{a}}$ & $3.49 \pm 0.18^{\mathrm{b}}$ & $3.64 \pm 0.14^{\mathrm{a}}$ \\
\hline Odour & $\begin{array}{c}4.78 \pm 0.18 \\
\mathrm{a}\end{array}$ & $2.02 \pm 0.28^{b}$ & $4.80 \pm 0.23^{\mathrm{a}}$ \\
\hline Taste & $\begin{array}{c}4.75 \pm 0.18 \\
\mathrm{a}\end{array}$ & $3.55 \pm 0.18^{b}$ & $4.69 \pm 0.19^{\mathrm{a}}$ \\
\hline Chewiness & $\begin{array}{c}4.19 \pm 0.19 \\
\mathrm{a}\end{array}$ & $3.25 \pm 0.15^{b}$ & $4.34 \pm 0.29^{\mathrm{a}}$ \\
\hline Porosity & $\begin{array}{c}4.59 \pm 0.23 \\
\mathrm{a}\end{array}$ & $4.23 \pm 0.31^{\mathrm{b}}$ & $4.65 \pm 0.25^{\mathrm{a}}$ \\
\hline
\end{tabular}

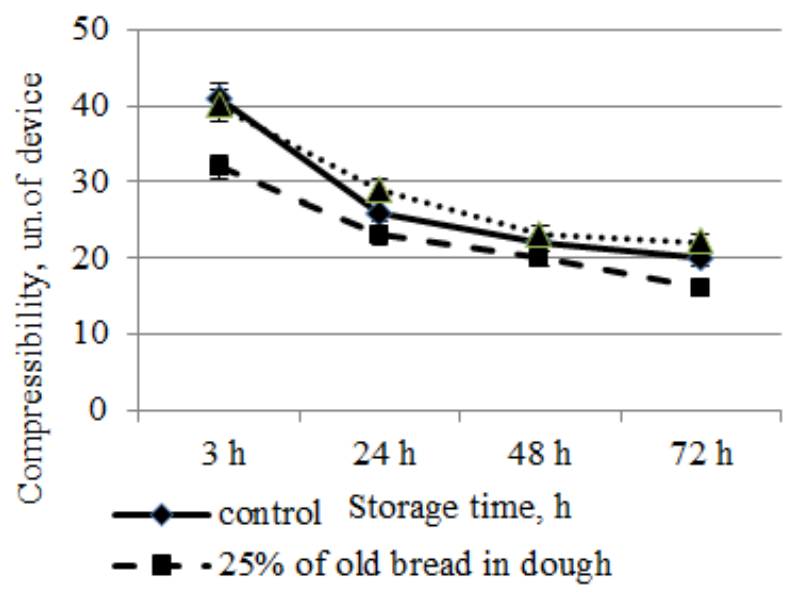

Fig. 6. Change in compressibility of bread crumb during storage.

\section{Discussions}

Our results bring insights into the impact of old recycled bread on the quality of new bread butch. Study has shown that flour and bread crumbs mixture is rich environment for microorganisms feeding. But biotechnological properties of sourdough were worse in such nitrogen-rich and reducing sugar-rich environments. The most apparent physical change related to the development of fermentation in the dough is the increase in its volume [9, 14]. Our data have shown than when quantity of old bread reduced, the volume of sourdough reduced too. It is known that the most significant carbohydrates from flour influencing the loaf volume are reducing sugar, such as glucose, fructose and sucrose [16-18]. When the concentration of glucose and fructose is elevated enough, the maltose concentration in dough is also mounted due to amylase, a starch debasing enzyme in flour, which is continuously generating new glucose and maltose from flour starch and bread starch $[18,19]$. It is obvious that the sugar amount in the experimental leaven were enough for fermentation. With the exception of sourdough made from $100 \%$ bread instead of flour. It is known that in baked bread amylase is inactivated [20]. That is why when $100 \%$ of flour were replaced by old bread crumbs, the reducing sugar content reduced (Fig. 4).

The decrease in the volume of sourdough with bread may be due to the fact that all biopolymers in bread are not in their native state. Proteins, starches and pentosanes lose their native properties during heat treatment, and therefore cannot retain foam and gas [2225 ]. Therefore, the volume of sourdough with bread was less.

When the old bread was in sourdough, the quality of the new bread was better than when the bread was used in the dough (Table 2). This is may be due to the fact that the polymers of breadcrumbs during baking were subjected to heat treatment and have changed their properties. They differ from polymers of native flour [21-24]. Therefore, replacing part of the flour with breadcrumbs leads to deterioration in the bread. However, when chemical compounds of bread crumbs 
were fermented in sourdough, it favorably affected the bread quality. The content of alcohol and volatile acids in the bread with old bread fermented in sourdough (Table 2) was comparable to the control. It contributed to the improvement in the taste and smell of bread compered bread made with old bread in dough.

When the compressibility of the crumb during storage was studied, it was found that bread made with bread in the dough had worse compressibility than bread made with fermented old bread in sourdough. When the bread was fermented in a sourdough, the crumb compressibility was the same as that of the control (fig. 6 ). This means that the fermentation of old bread into sourdough slowed down staling compared to the samples with old bread in the dough.

When sterile bread slices were infected with a pure mold culture Penicillium chrysogenum, it was established that the growth of mold colonies was absent during the entire storage period ( 7 days) in all samples. This indicated that bread recycling in dough does not affect the microbial spoilage of bread. It is because sourdough fermentation is also associated with antifungal and anti-bacterial properties that can improve bread shelf-life [25, 26]

Yet our knowledge of the mechanism of old bread impact on the fermentation activity of yeast and lactic acid bacteria is still limited. Here we show how old bread crumbs impact the quality of sourdough and bread.

\section{Conclusions}

Yeast and non-spore-forming bacteria were found in old bread used for recycling, but they were not detected in new bread batch immediately after baking. Old recycled bread did not significantly affect the microbial contamination of new bread, especially in terms of moulds and yeasts.

Data obtained shown that when the content of bread in sourdough increased, no nutrients for lactic acid bacteria and yeast (reducing sugars and amine nitrogen) decreased. The deterioration of the sourdough quality was not associated with a nutrient deficiency. $25 \%$ of the bread in the sourdough was good nutrition for microorganisms, and it didn't cause deterioration in the quality of the dough and bread, in contrast to when $25 \%$ of the old bread was introduced in the dough, not in the sourdough.

When $25 \%$ of recycling old bread was in the sourdough, the quality of the bread was comparable to the control, but the crumbliness was 1.5 times less compared to the control, which indicates a slowing down of the staling process in bread made with recycled bread in sourdough.

Bread made with fermented old bread in sourdough had sensory characteristics (crust shape, surface, crust color, taste, odour, chewiness and porosity) comparable to the control.

According to the results of the study, a new technology for processing old bread was developed, which allows increasing the amount of recycling old bread in comparison with the methods existing in Russia.

\section{References}

[1] A. Kosovan, Rules for the organization and conduct of the technological process at the baking enterprises, GOSNIIHP, Moscow (1999).

[2] J. Hamelman, Bread: A Baker's Book of Techniques and Recipes, Wiley, New York, (2012).

[3] S.P. Cauvain, L.S. Young, Technology of Breadmaking, Springer, BakeTran, UK(2007).

[4] G. Medvedev, Method for the production of crackers from stale and / or deformed bread, Patent of USSR no. 4394930/13, A21D13/00(1988).

[5] M. Fayvishevsky, V. Makrushin, Method for the production of extruded products such as bread sticks, Patent of the Russian Federation no. 2112380, A21D13/08 (1998).

[6] A. Demidov, Production and use of highly sugared enzymatic semi-finished products in the baking industry, MGAPP, Moscow (1983).

[7] O. Berdyshnikova, M. Kostyuchenko, Materials of the All-Russian Scientific and Practical Conference, All-Russian Research Institute of Butter Making and Cheese Making, Uglich (2012).

[8] Bread + Pastries and Confectionery, Almanac, Hamburg (2011).

[9] O. Afanasjeva, Microbiology of bakery production, Beresta, Saint-Peterburg(2003).

[10] K. de V Blackburn, Microbiological food spoilage, Profession, St. Petersburg(2008).

[11] M. Piotrowska, Biotechnology and Food Science, 77, 1 (2013).

[12] L. Kuznetsova, O. Savkina, L. Usova, Bread products, 3 (2017).

[13] A. Kosovan, The collection of modern technology of bakery products, Moscow printing house, Moscow (2008).

[14] L. Puchkova. Laboratory Workshop on Bakery Technology, GIORD, Saint-Petersburg (2004).

[15] N. Dubrovskay, O. Savkina, L. Kuznetsova, O. Parakhina, L. Usova, Agronomy Research, 17, S2 (2019).

[16] L. Puckova, R.Polandova, I. Matveeva, Technology of bread, pastry and pasta. Part 1. Bread technology, GIORD, Moscow (2019).

[17] C.Verheyen, A. Albrecht, D.Elgeti, M. Jekle, Food Research International, 76, 3 (2015).

[18] C. Verheyen, Structural investigations of yeasted wheat dough - the impact of $\mathrm{CO} 2$ and glutathione,TechnischeUniversität, München (2016).

[19] N. Struyf, J. Verspreet, C.M. Courtin, Journal of Cereal Science, 69 (2016).

[20] B.K. Patel, R.D. Waniska, K. Seetharaman, Journal of Cereal Science, 42, 2 (2005). 
[21] H. Singh, Food Chemistry, 90, 1-2 (2005).

[22] A.S Sivam, D. Sun-Waterhouse, S.Quek, C.O. Perera, Journal of Food Science, 75, 8 (2010).

[23] D. Fessas, A. Schiraldi, Journal of Thermal Analysis and Calorimetry, 61 (2000).

[24] M. Schirmer, M. Jekle, T. Becker, Procedia Food Science, 1 (2011).

[25] R. Rinaldi, M.Paciulli, G.Caligiani, E.Sgarbi, Journal of Food Science and Technology, 52, 10 (2015).

[26] E. Torrieri, O. Pepe, V.Ventorino, P. Masi, LWTFood Science and Technology, 56, 2 (2014). 